\section{Materials by Accident}

The stories of accidental discoveries are many, and they are probably all significantly embellished in the great tradition of urban (or scientific) mythology.

While some are fairly well documented, others only survive as acknowledged myths, the full story having been lost in the passage of thousands of years. Glass is supposed to have been discovered as a result of a camp-fire on a sandy Mediterranean beach, and coppersmelting by an attempt to attach a decorative piece of malachite to a clay pot before firing it in some Sumerian kiln. Who knows? It is almost certain, though, that some kind of accident led to these discoveries.

This key method of materials development has not been superseded in the modern age. We are all taught of Harry Brearley's accidental discovery of stainless steel as part of a war effort in 1913. He threw out a sample of an iron alloy that failed to live up to his hopes for a new gun-barrel material, and later noticed its failure to rust among all of the other alloys on the scrap-heap. This discovery solidified the reign of his home town, Sheffield, as the high temple of specialty steel production in the United Kingdom.

If we are to believe all of the storiessome of which are promulgated by the owners of the resulting patents-then nylon, polyethylene, lexan ${ }^{\circledR}$, teflon ${ }^{\circledR}$, and the process of rubber vulcanization were all discovered by accident. According to General Electric's advertising, the discovery of lexan ${ }^{\circledR}$ leaned heavily upon the assistance of the laboratory cat, which demonstrated the strength of the material by knocking a beaker of it to the floor, shattering the glass beaker but leaving the solidified, glassily clear and mechanically resilient lexan, with an embedded stirrer so it looked like some bizarre lollipop. Think what might have been missed if GE had instead developed and used the legendary "better mousetrap" and dispensed with the cat. ${ }^{\dagger}$

The English like to tell stories that

\footnotetext{
t"If a man...build[s] a better mousetrap than his neighbor, tho' he build[s] his house in the woods, the world will make a beaten path to his door" (Ralph Waldo Emerson).
}

reflect badly upon the French, so in British universities the story of the discovery of a reliable technique for steel extrusion is frequently related in lectures on materials processing. It seems that the problem was causing great frustration to a certain French. Dejectedly, he is supposed to have taken comfort in a bottle of wine, which was hurled, once emptied, into the extrusion press in his lab. The next test-run worked near-perfectly, and to this day the extrusion of steel is accomplished using a lubricant with a composition very close to that of ordinary bottleglass, which has just the right viscosity and wetting properties at the extrusion temperature. The name of the Sejournet Process celebrates its supposedly moody discoverer.

Aluminum-copper alloys have been
Aluminum-copper alloys
have been the subject of
two well-documented
accidental discoveries,
which must be a record.

the subject of two well-documented accidental discoveries, which must be a record. First, the strain-aging process was discovered by Wilm in 1908. Then the resistance of these alloys to electromigration damage in microcircuits was discovered by accident in a series of experiments at IBM. A massive effort to improve the electromigration resistance of pure aluminum interconnects called into service "acres" of electron-beam evaporators and testing units to investigate the effects of process variables, but the material from one of the evaporators always displayed much better results than any other-by an order of magnitude or more. The electron beam in this particular unit was eventually found to be misaligned and was hitting both the aluminum charge and the water-cooled copper crucible that contained it, allowing a dilute aluminumcopper alloy to be formed instead of the intended pure aluminum test structures. Intense follow-up experimentation in hundreds of labs has barely improved upon that original accidental result without which we would not be able to make high-speed, high-density microcircuits like the ones in the computer that I am typing on.

It was another aluminum alloy (with manganese, iron, or chromium) that produced the startling discovery of quasicrystals in 1984. This must have looked, at first, like a disappointing result of an attempt to form a metallic glass by rapid solidification.

In matters of observational sciencr said Pierre Curie (another accid. prone French scientist), fortune fav prepared mind; so it is importar st only to have accidents, but alsc av the ability to recognize the or rtu ties that they present. Of cou cannot have these kinds of accia. unless you do some experiments. $\operatorname{Tr}$. I might, I cannot uncover any s: . lucky accidents that have occurred during the process of a theoretical investigation or a computer simulation-for obvious reasons, really: These investigations only produce on the basis of what goes into them. Garbage in-garbage out is the only kind of "accident" we can expect from this kind of research. This is not to say that the research is without value, of course; only that it does not provide very much opportunity for serendipitous results.

Long live experimenters-especially the kind who are willing to try "dumb" ideas and make "stupid mistakes." While others cautiously predict what new materials developments we might see in the coming millennium, I confidently guarantee that more major new materials, materials classes, materials processes, and materials properties will be discovered by accident in the lab than by design in the computer-at least if experimental research st:1l attracts sufficient funding in an age of supercomputing grand challenges and virtual reality. If your toe catches something in a virtual environment, yisu don't trip. Let's hear it for real real' $y$, and life's little stumbles, too. They :are trying to tell you something, if you have the toes to feel them, and the ears to hear what your toes are telling you.

ALEX $K_{\text {ING }}$ 